\title{
Cardiothoracic Anesthesia, Respiration and Airway
}

\section{Trendelenburg position, head elevation and a midline position optimize right internal jugular vein diameter}

\author{
[La position de Trendelenburg, l'élépation de la tête et une position médiane \\ augmentent le diamètre de la veine jugulaive interne droite]
}

Gareth Parry BM FRCA

\begin{abstract}
Purpose: The right internal jugular (RIJ) is commonly used to provide central venous access, and success of cannulation shows a positive correlation with the vein's diameter. The purpose of this study is to establish the patient position resulting in the largest RIJ diameter.
\end{abstract}

Method: 2D ultrasound was used to measure RIJ diameter, in varying body positions, in 21 healthy volunteers.

Results: In the neutral position (table flat, head on the table in midline) the RIJ diameter was (mean \pm standard deviation) $9.2 \pm 2.18$ $\mathrm{mm}$. A small pillow under the head increased RI) diameter ( $10.6 \pm$ $2.16 \mathrm{~mm}, P<0.00 \mathrm{I})$. Trendelenburg tilt of $15^{\circ}$ increased RIJ diameter $(\mid 2.1 \pm 2.34 \mathrm{~mm}, P<0.00 \mathrm{I})$. In the Trendelenburg position ( $15^{\circ}$ of tilt), a small pillow under the head further increased RIJ diameter $(|3.3 \pm 2.26, \mathrm{~mm} P<0.00|)$, palpating for the carotid artery decreased RIJ diameter $(8.2 \pm 1.98 \mathrm{~mm}, P<0.00 \mathrm{I})$, and rotation of the head $45^{\circ}$ to the left did not reduce RIJ diameter significantly ( $11.7 \pm 2.52 \mathrm{~mm}, P=0.12)$.

Conclusion: The patient position to achieve maximal RIJ diameter cannulation is: $15^{\circ}$ of Trendelenburg tilt; a small pillow or head ring under the head; the head in or close to midline; and after palpation of the carotid artery, it should be released prior to vein cannulation.

Objectif : La veine jugulaire interne droite (IID) est couramment utilisée comme accès veineux et le succès de la mise en place d'une canule montre une corrélation positive avec le diamètre de la veine. L'objectif de notre étude était de déterminer la position du patient qui favorise le diamètre maximal de la veine JID.

Méthode : L'échographie 2D a été utilisé pour mesurer le diamètre de la JID selon diverses positions du corps chez 2 I volontaires en bonne santé.
Résultats : En position neutre (à plat, tête sur la table dans un plan médian) le diamètre de la JID était de (moyenne \pm écart type) 9,2 \pm $2,18 \mathrm{~mm}$. Un petit coussin sous la tête augmentait le diamètre de la JID $(10,6 \pm 2,16 \mathrm{~mm}, P<0,001)$. Une inclinaison de Trendelenburg de $15^{\circ}$ l'augmentait aussi $(|2,1 \pm 2,34 \mathrm{~mm}, P<0,00|)$. En position de Trendelenburg (inclinaison de $15^{\circ}$ ), un coussin sous la tête l'augmentait encore plus $(\mid 3,3 \pm 2,26 \mathrm{~mm}, P<0,001)$, la palpation de l'artère carotide le diminue $(8,2 \pm 1,98 \mathrm{~mm}, P<0,00$ l) et la rotation de la tête de $45^{\circ}$ vers la gauche ne le réduit pas de façon significative ( I I,7 $\pm 2,52 \mathrm{~mm}, P=0,12)$.

Conclusion : La position du patient qui permet d'obtenir le diamètre maximal de la JID pour la mise en place d'une canule est : la position de Trendelenburg avec une inclinaison de $15^{\circ}$; un petit coussin ou un anneau lesté sous la tête; la tête dans un plan médian ou s'en approchant ; après la palpation de l'artère carotide, toute pression cessée avant l'introduction d'une canule.

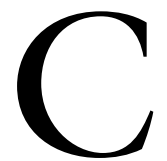

ANNULATION of the right internal jugular vein (RIJ) is a common method of providing central venous access. The larger the cross-sectional area of the RIJ, the easier it should be to locate. A significant correlation has been shown between increased RIJ diameter, and first pass success of RIJ cannulation. ${ }^{1}$ The purpose of this study was to identify the position that results in the largest diameter of RIJ, and thus the greatest chance of successful first pass cannulation of that vein.

From the Department of Anesthesia, University of British Columbia, Vancouver, British Columbia, Canada. Address correspondence to: Dr. Gareth Parry, Department of Anaesthetics, University of Wales College of Medicine, Heath Park,

Cardiff CF14 4XN, United Kingdom. Phone: 0292074 3110; Fax: 0292074 7203; E-mail: garethandantonia@ntlworld.com Accepted for publication June 18, 2003

Revision accepted November 13, 2003. 
TABLE I Average right internal jugular vein diameter in different positions

\begin{tabular}{lll}
\hline Position of subject & Mean \pm standard deviation \\
\hline A & Table flat, subject supine with head midline on table & $9.2 \pm 2.18 \mathrm{~mm}$ \\
B & Table flat, subject supine with head on small pillow & $10.6 \pm 2.16 \mathrm{~mm}$ \\
C & $15^{\circ}$ Trendelenburg tilt, head on table & $12.1 \pm 2.34 \mathrm{~mm}$ \\
D & $15^{\circ}$ Trendelenburg tilt, head on small pillow & $13.3 \pm 2.26 \mathrm{~mm}$ \\
E & $15^{\circ}$ Trendelenburg tilt, head on small pillow and rotated $45^{\circ}$ to left & $12.6 \pm 2.06 \mathrm{~mm}$ \\
F & $15^{\circ}$ Trendelenburg tilt, head on small pillow and carotid artery gently palpated & $9.0 \pm 2.32 \mathrm{~mm}$ \\
$\mathrm{G}$ & $15^{\circ}$ Trendelenburg tilt, head on small pillow and rotated $45^{\circ}$ to left and carotid artery gently palpated & $10.1 \pm 1.73 \mathrm{~mm}$ \\
$\mathrm{H}$ & $15^{\circ}$ Trendelenburg tilt, head on table and rotated $45^{\circ}$ to left & $11.7 \pm 2.52 \mathrm{~mm}$ \\
I & $15^{\circ}$ Trendelenburg tilt, head midline on table and carotid artery gently palpated & $8.2 \pm 1.98 \mathrm{~mm}$ \\
$\mathrm{~J}$ & $15^{\circ}$ Trendelenburg tilt, head on table and rotated $45^{\circ}$ to left and carotid artery gently palpated & $8.6 \pm 2.65 \mathrm{~mm}$ \\
\hline
\end{tabular}

TABLE II Comparisons of right internal jugular diameter in different positions

\begin{tabular}{|c|c|c|c|c|}
\hline \multicolumn{3}{|l|}{ Position } & \multicolumn{2}{|l|}{ Position } \\
\hline Section 1. & No Trendelenburg tilt & & $15^{\circ}$ Trendelenburg tilt & \\
\hline A & $(9.2 \pm 2.18 \mathrm{~mm})$ & $v s$ & $\mathrm{C} \quad(12.1 \pm 2.34 \mathrm{~mm})$ & $P<0.001$ \\
\hline B & $(10.6 \pm 2.16 \mathrm{~mm})$ & ps & $\mathrm{D} \quad(13.3 \pm 2.26 \mathrm{~mm})$ & $P<0.001$ \\
\hline Section 2 . & Head on bed & & Head raised by a small pillow & \\
\hline A & $(9.2 \pm 2.18 \mathrm{~mm})$ & vs & $\mathrm{B} \quad(10.6 \pm 2.16 \mathrm{~mm})$ & $P<0.001$ \\
\hline $\mathrm{C}$ & $(12.1 \pm 2.34 \mathrm{~mm})$ & vs & $(13.3 \pm 2.26 \mathrm{~mm})$ & $P<0.001$ \\
\hline $\mathrm{H}$ & $(11.7 \pm 2.52 \mathrm{~mm})$ & $v s$ & $(12.6 \pm 2.06 \mathrm{~mm})$ & $P<0.001$ \\
\hline I & $(8.2 \pm 1.98 \mathrm{~mm})$ & $v s$ & $(9.0 \pm 2.32 \mathrm{~mm})$ & $P<0.05$ \\
\hline $\mathrm{J}$ & $(8.6 \pm 2.65 \mathrm{~mm})$ & $v s$ & $\mathrm{G} \quad(10.1 \pm 1.73 \mathrm{~mm})$ & $P<0.001$ \\
\hline Section 3 . & Head in midline & & Head rotated $45^{\circ}$ to left & \\
\hline $\mathrm{C}$ & $(12.1 \pm 2.34 \mathrm{~mm})$ & $v s$ & $\mathrm{H} \quad(11.7 \pm 2.52 \mathrm{~mm})$ & $P=0.12$ \\
\hline $\mathrm{D}$ & $(13.3 \pm 2.26 \mathrm{~mm})$ & vs & $(12.6 \pm 2.06 \mathrm{~mm})$ & $P<0.001$ \\
\hline G & $(10.1 \pm 1.73 \mathrm{~mm})$ & $v s$ & $(9.0 \pm 2.32 \mathrm{~mm})$ & $P<0.001$ \\
\hline $\mathrm{J}$ & $(8.6 \pm 2.65 \mathrm{~mm})$ & ps & I $\quad(8.2 \pm 1.98 \mathrm{~mm})$ & $P=0.49$ \\
\hline Section 4 & No carotid artery pressure & & Palpating for carotid artery & \\
\hline $\mathrm{C}$ & $(12.1 \pm 2.34 \mathrm{~mm})$ & $v s$ & $\mathrm{I} \quad(8.2 \pm 1.98 \mathrm{~mm})$ & $P<0.001$ \\
\hline $\mathrm{D}$ & $(13.3 \pm 2.26 \mathrm{~mm})$ & $v s$ & $(9.0 \pm 2.32 \mathrm{~mm})$ & $P<0.001$ \\
\hline $\mathrm{E}$ & $(12.6 \pm 2.06 \mathrm{~mm})$ & vs & $(10.1 \pm 1.73 \mathrm{~mm})$ & $P<0.001$ \\
\hline $\mathrm{H}$ & $(11.7 \pm 2.52 \mathrm{~mm})$ & vs & $(8.6 \pm 2.65 \mathrm{~mm})$ & $P<0.001$ \\
\hline
\end{tabular}

\section{Methods}

After explanation of the methodology, 21 anesthesiologists and recovery room nurses at Vancouver General Hospital volunteered for the study, and gave their informed consent. All subjects were ASA I or II, no subject had had neck surgery, and no subject was fasting. 2D ultrasonography [Hewlett Packard Sonos 2000 (Palo Alto, CA, USA) at $5 \mathrm{MHz}$ ] was used to measure the internal diameter of the RIJ, in an anterior-posterior plane, at the level of the cricoid cartilage. Different body positions were adopted, simulating patient positioning that may be used while attempting to cannulate the RIJ (Table I, left column). The mean of the higher two of three measurements was recorded, in each of the ten positions. A second observer palpated the carotid artery with the minimum necessary pressure to feel the arterial pulse. All results are presented as mean \pm standard deviation. A paired Student's t test was used to test for significance. A $P$ value of $\leq 0.05$ was used to indicate statistical significance.

\section{Results}

The RIJ was easy to visualize in all subjects. The mean RIJ diameter with the table flat, the head resting on the table, and in the midline (Table I, position A) was 9.2 $\pm 2.18 \mathrm{~mm}$, increasing to $10.6 \pm 2.16 \mathrm{mmm} P<0.001$ (position B) when a small pillow was inserted under the head. The mean RIJ diameter with $15^{\circ}$ Trendelenburg tilt was $12.1 \pm 2.34 \mathrm{~mm}$ (position $\mathrm{C}$ ), increasing to $13.3 \pm 2.26 \mathrm{~mm} P<0.001$ (position $\mathrm{D}$ ), when a small pillow was used. In Trendelenburg tilt: rotation of the head $45^{\circ}$ to the left decreased the diameter of the RIJ $11.7 \pm 2.52 \mathrm{~mm}$ (position $\mathrm{H}$ ), as compared to midline (position C), $P=0.12$; and light palpation of the carotid artery reduced the diameter of the RIJ $8.2 \pm$ 
$1.98 \mathrm{~mm}$ (position I), as compared to no palpating pressure (position $\mathrm{C}$ ), $P<0.001$.

Fifteen degree Trendelenburg tilt gave significantly larger RIJ diameters than a flat table (Table II, section 1). The use of a small pillow under the head gave significantly larger RIJ diameters than all corresponding positions without a pillow (Table II, section 2). Rotation of the head $45^{\circ}$ to the left reduced RIJ diameter compared to corresponding positions with the head in the midline, but not in all positions (Table II, section 3). Palpation of the carotid artery significantly reduced RIJ diameter compared to corresponding positions without carotid artery palpation (Table II, section 4 ).

Position D $\left(15^{\circ}\right.$ Trendelenburg tilt, the head on a pillow in the midline, with no carotid artery pressure), was the position with the greatest RIJ diameter (13.3 $\pm 2.26 \mathrm{~mm}$ ); the difference was statistically significant when compared to all other positions (Table II).

\section{Discussion}

Internal jugular cannulation with sonographic guidance is more likely to result in success as compared to a blind technique, is considered safer, and has also been found to be quicker. ${ }^{1-6}$ However, portable sonographic devices are not always available, and sometimes achieving central venous access is difficult. Logically, the larger a target, the easier it is to hit and one should aim to maximize the diameter of the RIJ before attempting to cannulate it. It has been shown that the larger the diameter of the RIJ the more likely one is to achieve first pass cannulation ${ }^{1}$ and therefore the less the chance of complications. The RIJ is usually very compliant; ${ }^{7}$ relatively small changes in pressure produce large changes in volume and thus in cross sectional area. Armstrong ${ }^{8}$ showed that maneuvers that increase central venous return increase RIJ diameter. This observer also found $15^{\circ}$ Trendelenburg tilt significantly increased RIJ diameter, as compared to a flat table (position A vs position $\mathrm{C}, P<0.001$ ). At $20^{\circ}$ or more of Trendelenburg tilt the subjects started to slide on the table, and no measurements were taken.

Reduction in cross-sectional area will occur with any external pressure on the RIJ. Armstrong ${ }^{8}$ showed palpation of the carotid artery significantly reduced the diameter of the RIJ. This reduction by carotid artery pressure is also seen in the Trendelenburg position (position $\mathrm{C} v s$ position $\mathrm{I}, P<0.001$ ).

A significant increase in RIJ diameter can be accomplished by positioning a small pillow under the head (position $\mathrm{A}$ vs position $\mathrm{B}, P<0.001$ ), this is also found in the Trendelenburg position (position $\mathrm{C} v$ s position $\mathrm{D}$, $P<0.001)$. Increased tension of structures in the neck, either compressing or preventing expansion of the RIJ is thought to be the mechanism. Armstrong ${ }^{8}$ showed a marked reduction in diameter of the RIJ when a bolster was positioned under the shoulders probably through the same, but more exaggerated mechanism.

In the Trendelenburg position, rotation of the head $45^{\circ}$ to the left reduced the size of the RIJ with a pillow (position $\mathrm{D}$ vs position $\mathrm{E}, P<0.001$ ) but not without (position $\mathrm{C}$ vs position $\mathrm{H}, P=0.12$ ); a similar reduction was shown by Muhammad. ${ }^{9}$

First pass success in cannulation should be the objective. Blind puncture techniques require the optimum patient position in order to increase success. In self ventilating subjects, the maximum RIJ diameter can be accomplished in the following fashion: $15^{\circ}$ Trendelenburg tilt; a small pillow or head ring under the head; the head in or close to the midline; carotid artery palpation released prior to insertion of the RIJ line. The effect of positive pressure ventilation on RIJ size was not examined. Increased intrathoracic pressure is likely to increase RIJ diameter in all positions.

\section{References}

1 Gordon AC, Saliken JC, Johns D, Owen R, Gray RR. US-guided puncture of the internal jugular vein: complications and anatomic considerations. J Vasc Interv Radiol 1998; 9: 333-8.

2 Caridi JG, Hawkins IF Jr, Wiechmann BN, Pevarski DJ, Tonkin JC. Sonographic guidance when using the right internal jugular vein for central vein access. Am J Roentgenol 1998; 171: 1259-63.

3 Docktor B, So CB, Saliken JC, Gray RR. Ultrasound monitoring in cannulation of the internal jugular vein: anatomic and technical considerations. Can Assoc Radiol J 1996; 47: 195-201.

4 Koski EM, Subonen M, Mattila MA. Ultrasound-facilitated central venous cannulation. Crit Care Med 1992; 20: 424-6.

5 Keenan SP. Use of ultrasound to place central lines. J Crit Care 2002; 17: 126-37.

6 Teichgraber UK, Benter T, Gebel M, Manns MP. A sonographically guided technique for central venous access. Am J Roentgenol 1997; 169: 731-3.

7 Denys BG, Uretsky BF. Anatomical variations of internal jugular vein location: impact on central venous access. Crit Care Med 1991; 19: 1516-9.

8 Armstrong PJ, Sutherland R, Scott DH. The effect of position and different manoeuvres on internal jugular vein diameter size. Acta Anaesthesiol Scand 1994; 38: 229-31.

9 Muhammad JK, Pugh ND, Boden L, Crean SJ, Fardy $M J$. The effect of head rotation on the diameter of the internal jugular vein: implications for free tissue transfer. J Craniomaxillofac Surg 2001; 29: 214-8. 